\title{
Training in 21st Century Working Life Skills: How to Support Productivity and Well-Being in Multi-Locational Knowledge Work
}

\author{
Kirsi Sjöblom¹, Heidi Lammassaari'1 , Lauri Hietajärvi' ${ }^{1}$, Kaisu Mälkki², Kirsti Lonka1 \\ ${ }^{1}$ University of Helsinki, Helsinki, Finland \\ ${ }^{2}$ University of Tampere, Tampere, Finland \\ Email: kirsi.sjoblom@helsinki.fi, https://www.linkedin.com/in/kirsisjoblom
}

How to cite this paper: Sjöblom, K., Lammassaari, H., Hietajärvi, L., Mälkki, K., \& Lonka, K. (2019). Training in 21st Century Working Life Skills: How to Support Productivity and Well-Being in Multi-Locational Knowledge Work. Creative Education, 10, 2283-2310.

https://doi.org/10.4236/ce.2019.1010164

Received: October 1, 2019

Accepted: October 28, 2019

Published: October 31, 2019

Copyright $\odot 2019$ by author(s) and Scientific Research Publishing Inc. This work is licensed under the Creative Commons Attribution International License (CC BY 4.0). http://creativecommons.org/licenses/by/4.0/

\section{Open Access}

\begin{abstract}
Along with the rapid development of digital technology and the increasing proportion of knowledge work, work is becoming decreasingly defined by time and place, and more diverse in terms of both. As digital tools and multi-locational spaces become focal parts of human performance, the optimal use of these resources requires not only the ability to mechanically use them, but also the ability to develop useful behavioral strategies and practices related to them. In fact, modern work requires new kinds of skills from both employees and employers, and useful work practices need to be developed at both the individual and organizational level. This study presents a training program that aims to support well-being and productivity at multi-locational knowledge work by developing the participants' awareness skills and behavioral strategies related to knowledge work, digital tools and physical spaces as well as by facilitating the development process in the participating organizations. Fifteen trainees from eight organizations attended the program and a larger sample of employees $(n=189)$ responded to the questionnaires. The approach of the study was design research, and we applied mixed methodology: ANOVAs and qualitative content analysis. This study shows the organizations' and individuals' diverse needs regarding using multi-locational spaces and digital tools. It concludes that individuals and organizations can benefit from training in the use of modern spaces and tools in ways that support productivity and well-being. From the theoretical and practical perspective, the study contributes to the current understanding of how to utilize multi-locational spaces and digital tools in ways that support the productivity and well-being of employees.
\end{abstract}

\section{Keywords}

Knowledge Work, Multi-Locational Work, Digital Tools, Physical 
Environment, Organizational Culture, Training, Productivity, Well-Being, 21st Century Skills, Awareness Skills, Mindfulness, Behavioral Strategies, Motivation, Self-Determination Theory

\section{Introduction}

Along with the rapid development of digital technology and the increasing proportion of knowledge work, work is becoming decreasingly defined by time and place, and more diverse in terms of both (see e.g. Brinkley, 2006; Ojala \& Pyöriä, 2018; Rüdiger \& McVerry, 2007). While at best, the evolution of work may open up possibilities for employees in terms of unforeseen liberty and more purposeful usage of time and energy, previous research shows that it also has pitfalls (Sparks, Faragher, \& Cooper, 2001). Employees may lack boundaries and sufficient recovery from their work (Vartiainen \& Hyrkkänen, 2010; Zijlstra \& Sonnentag, 2006), and working in multi-locational spaces often comes with many distractions and hindrances (Bosch-Sijtsema, Ruohomäki, \& Vartiainen, 2010) such as a restless environment and difficulty identifying with the workplace.

A knowledge worker has been defined as anyone who creates, develops, manipulates, disseminates or uses knowledge to provide a competitive advantage or some other benefit that contributes towards the goals of an organization. Knowledge workers typically work in a team (whether local or virtual), and make extensive use of information and communications technology (ICT). (Harrison, Wheeler, \& Whitehead, 2004). As digital tools and multi-locational spaces become focal parts of human performance, the optimal use of these resources requires not only the ability to mechanically use them, but also the ability to develop useful behavioral strategies and practices related to them. Required transversal skills such as self-regulation and metacognition are now being taught at schools as part of $21^{\text {st }}$ century competencies (Lonka, 2018), but the workforce rarely receives such training, or it is scattered: One training may aim to enhance employees' ICTs kills while others focus on productivity, awareness skills or occupational health, but they rarely concentrate on the interplay of all these areas in everyday work. What is often overlooked is that modern environments and tools and the related practices are crucial for the productivity and well-being of knowledge workers (e.g. Bosch-Sijtsema, Ruohomäki, \& Vartiainen, 2010; Vartiainen \& Hyrkkänen, 2010).

In order to harness the psychological resources available to employees and to support the thriving of valuable human potential, useful work practices need to be developed at both the individual and organizational level (e.g. Hakkarainen, Palonen, Paavola, \& Lehtinen, 2004; Pashler, 1994; Salo, Salmela, Salmi, Numminen, \& Alho, 2017; Vartiainen \& Hyrkkänen, 2010; Zijlstra \& Sonnentag, 2006). We argue that this can be done by developing training programs targeted at tackling these challenges. To demonstrate this argument, we first describe in more detail the kind of support that is needed and why. Second, we present a 
training program developed to respond to these specific challenges; and third, we present the empirical results of the first round of training.

\section{Theoretical Framework}

\subsection{Importance of Proactive Behavioral Strategies and Awareness Skills in Multi-Locational Knowledge Work}

Multi-locational work refers to work that by definition is carried out in many different locations, such as office, home, public spaces such as cafes or airports, and mobile locations such as cars or trains (Hislop \& Axtell, 2009). Multi-locational work environments are in many ways less clearly defined than more traditional ones. At the same time, they tend to include more stimuli through different modalities. On a daily basis, employees operate using numerous digital applications and communication channels, perhaps collaborate with several fixed-term teams, and physically relocate from one place to another. In addition to the physical premises at which the employees are located, they are simultaneously present in several digital communities (e.g. Nenonen et al., 2009; Vartiainen \& Hyrkkänen, 2010).

The complexity of modern environments creates certain challenges regarding human executive functions. The balance between an individual's self-regulation skills and the regulation provided by the environment can be seen as either constructive or destructive friction: Individuals who have strong abilities to self-regulate tend to thrive in environments that allow a higher level of self-directedness, whereas individuals who are not equally used to regulating their own behavior may find themselves overwhelmed by the demands they are facing (Vermunt \& Verloop, 1999). The vaguer and more undefined the environment and the less it provides structure, the more an individual needs to regulate their own functioning.

The need to self-regulate in order to harness one's cognitive input and carry out complex tasks in work settings is not new (e.g. Kanfer \& Kanfer, 1991). However, contemporary work environments have even more stimuli, options and attractions than the more traditional ones. The more the environment pulls the individual in different directions, the greater is the need for self-regulation and deliberately chosen strategies (on self-regulation, see e.g. Boekaerts, Zeidner, \& Pintrich, 2000).

Perhaps partly due to these challenges, interest has been growing in both the academic world and working life in ways to train the mind to be better able to cope with the overflow of information and stimuli and increasingly complex surroundings. As one approach, mindfulness practice, which refers to nonjudgmental awareness of what is happening in the present moment (e.g. Bishop et al., 2004), has shown to be beneficial for the psychological functioning of employees (e.g. Janssen, Heerkens, Kuijer, Van Der Heijden, \& Engels, 2018), and many corporate organizations include mindfulness practice in their employee support programs (Gelles, 2015). Indeed, awareness and clarity regarding what is happening in the present moment is a fundamental basis for determining the 
strategies required by a given situation and self-regulating accordingly, be this in terms of productivity or well-being.

The nature of knowledge work and the fact that the majority of its employees are high-functioning experts may falsely lead to the assumption that these employees inherently possess certain abilities to self-regulate and manage their mental resources. However, these skills are clearly distinct from the specific professional abilities of each employee. Current society demands of individuals a new set of skills and competencies in order for them to function effectively at work, as citizens and during their leisure time (Ananiadou \& Claro, 2009). For instance, finding ways to successfully cope with mental overload and stress is a global challenge that reaches beyond the workplace: the World Health Organization considers mental health and stress-related issues one of the most prevalent health risks globally and emphasizes the importance of developing the sustainability strategies required in different life domains (WHO, 2013). Many employees need assistance in learning skills such as stress management (Sparks, Faragher, \& Cooper, 2001), cognitive load management, or using modern tools (Ananiadou \& Claro, 2009).

In order to be productive in knowledge work (Harrison, Wheeler, \& Whitehead, 2004; Ramírez \& Nembhard, 2004), it is crucial to find ways to efficiently manage one's available psychological resources. Both individuals and organizations can make deliberate decisions and develop strategies for this, as we demonstrate in our empirical case.

\subsection{Knowledge Work Environments, Motivation and Well-Being}

According to current understanding of how to best support motivation, productivity, well-being and sustainable commitment at work, it is essential that the environment be supportive of the employees' basic psychological needs: autonomy, competence and relatedness (Deci \& Ryan, 2014). This applies not only to the social and cultural environment, but also to the physical environment that the individuals function in (Sjöblom, Mälkki, Sandström, \& Lonka, 2016). Autonomy refers to perceiving oneself as the origin or source of one's own behavior, competence refers to a sense of confidence and effectiveness in one's own actions, and relatedness refers to feeling connected to other individuals or one's community (Deci \& Ryan, 2000; Deci \& Ryan, 2014). The view of these needs being fundamental for healthy, effective psychological functioning is particularly central to self-determination theory, which is one of the most prevailing contemporary theories on human motivation, development and well-being (Deci \& Ryan, 2000; Ryan \& Deci, 2000; Ryan \& Deci, 2017). However, the importance of perceived autonomy and opportunities for individuals to be heard and make a difference in their social surroundings has also been acknowledged in occupational health research (e.g. Bakker \& Demerouti, 2007; Karasek \& Theorell, 1990).

Although modern multi-locational, digitally mediated knowledge work poses new challenges, it also opens up new possibilities to support the autonomy, competence and relatedness of employees. At best, this kind of work is very au- 
tonomous. Autonomy is also a focal characteristic of $21^{\text {st }}$ century work (Ananiadou \& Claro, 2009), and most organizations have indeed come a long way from the days when work was done in specific physical premises, started and finished at a certain time and was unambiguously monitored and directed by the manager in charge. Nowadays, an increasing number of work tasks are abstract and most essentially require intellectual and creative input, which cannot be fully designated to specific working hours or locations, or monitored or even observed from the outside.

In many cases, employees are free to choose the conditions that best support their work tasks and the best means to achieve the goals that are their responsibility. While this may seem optimal in many ways, potential challenges also arise. For example, the employee's role may become overly self-reliant: With fixed-term projects, changing team line-ups and team members coworking from multiple geographic locations and time zones, face-to-face or even virtual connections may be irregular and erratic. Sufficient communication and support from team members or superiors may not be self-evident.

While the characteristics of work are rapidly changing with employees now themselves regulating and managing their own work and employers facilitating this process and providing fruitful conditions for it, certain organizational practices may lag behind. For instance, employees may be required to report their use of working hours in detail, or laboriously apply for permission to work remotely for a day. This kind of external control is likely to impair employees' motivation (Deci \& Ryan, 2014), in particular if at the same time they are expected to take an ever more significant lead in their own work. Thus, the ongoing evolution of work is challenging not only employees but also leaders and organizations to be aware of the required changes and to renew their work practices (e.g. De Paoli, 2015). Management should be able to both offer the support required and genuinely enable an autonomous role for employees (Deci \& Ryan, 2000; Deci, Ryan, Gagné, Leone, Usunov, \& Kornazheva, 2001).

It is widely acknowledged that current and future working life demands new kinds of competencies of employees (Ananiadou \& Claro, 2009; Lonka et al., 2015). Examples of these competencies include the ability to collaborate in networked systems and to use digital tools, self-regulation and self-leadership, cognitive load management, novel thinking, creative problem-solving and interaction beyond cultural borders. These, and other transversal skills, are currently being included in the curricula of comprehensive schools worldwide in order to prepare children and adolescents for the demands of their future work. In working life, however, the need to develop these skills is not always acknowledged or supported. Depending on their prior experience, employees' abilities may vary greatly. If the need to receive sufficient support for developing focal competencies is not acknowledged, and consequently employees are unable to manage their work in the ways expected, this may have a crippling effect on motivation, performance and well-being at work (Deci \& Ryan, 2014; Ryan \& Deci, 2017). 
The experience of relatedness seems to be particularly interesting in new kinds of multi-locational work environments. Some findings suggest that in multi-locational work employees may encounter difficulties finding their coworkers and connecting with them, and informal interaction tends to be scarce (Bosch-Sijtsema, Ruohomäki, \& Vartiainen, 2010). Alternatively, when social encounters do happen, the employees may experience the encounters to be bursting with the need to connect, at times overrunning the time and space needed for work tasks, thus creating a sense of additional stress for the working day (Hislop \& Axtell, 2009). Multi-locational knowledge workers are generally able to utilize digital tools to connect with their coworkers in new ways; however, many of them appear to need more face-to-face encounters and interaction, for both formal and informal purposes (Bosch-Sijtsema, Ruohomäki, \& Vartiainen, 2010).

It is not uncommon for virtual environments to make effective communication challenging (Powell, Piccoli, \& Ives, 2004). Furthermore, the quality of connections and the consequent perceived relatedness and trust is also focal with regard to knowledge sharing, which is of interest to any knowledge intensive organization. The most valuable currency in knowledge work is human capital: The knowledge and abilities of the individuals, as well as their co-creations. It has been noted that in order for people to share knowledge and to want to share knowledge, informal interaction is essential (Ipe, 2003), and this form of interaction is most likely to be compromised in multi-locational work.

On the other hand, increasingly common multi-space offices may bring employees together in beneficial ways and enable more informal, spontaneous opportunities for interaction than more traditional workspaces. For example, some companies have found that moving to a multi-space office has created closer, more spontaneous interaction among employees and managers, which in turn has led to more knowledge sharing, collaboration and innovations (Huber, 2015). However, it is important to point out that a certain kind of environment does not alone ensure a certain nature for the activity. Although multi-space offices are often seen as inherently social and collaborative, a certain kind of physical environment, just like a certain kind of communal digital platform, does not yet guarantee that the environment will be social or collaborative or that the participants will experience a sense of relatedness or community. In order for a new social group to form and new shared practices to evolve, a deliberate supported group process is highly beneficial. Particular attention should be paid to this aspect of novel work environments (e.g. Nenonen et al., 2015).

\subsection{Role of Physical Environment and Digital Tools in Productivity and Well-Being in Knowledge Work}

In addition to directly affecting health and productivity in terms of, for example, lighting, noise and ergonomics (e.g. Parsons \& Hartig, 2000), the physical environment and tools also influence cognitive functioning and productivity in terms of their functionality. Environments and tools can take the user's abilities 
to the next level or, respectively, significantly impair the performance the users would be able to attain if they had the suitable means (Hutchins, 2000; Norman, 1993). Furthermore, well-functioning spaces and tools not only supplement the capabilities of users; they also contribute to users' perceptions of themselves as competent, autonomous agents belonging to that particular environment (Sjöblom, Mälkki, Sandström, \& Lonka, 2016).

Some of the core resources in knowledge work, in addition to human capital, are physical spaces and digital tools. In abstract, digitally mediated, multi-locational work, the functionality of tools may become even more focal, because without well-functioning tools, this work is simply not possible. However, workplaces may differ greatly as to what kind of resources they are able to offer their employees and how well these resources accommodate the work expected of them.

Typically, knowledge work includes different kinds of abstract tasks, for example, those that are carried out individually and quietly and those that are carried out collaboratively (El-Farr, 2009; Harrison, Wheeler, \& Whitehead, 2004). Workspaces do not always equally accommodate for all of these. One attempt to offer employees suitable premises for different kinds of tasks are multi-space offices, in which a group of employees do not have designated desks but are free to access different kinds of spaces depending on their needs and tasks at hand. Cost-efficiency is another asset of organizing work environments in this way (Gareis, 2003): Office space is expensive, and in traditional individual offices it is not uncommon for spaces to be empty for a large proportion of the time. This is particularly characteristic of multi-locational, digitally mediated work.

However, it is often not enough to simply move employees into a new environment and assume that new work practices will be directly adopted. To make use of potential and avoid pitfalls it is highly important to prepare for such a work environment change carefully. This includes surveying employee needs for different kinds of spaces in advance, emphasizing the process of settling into the new environment, inviting employees to play an active role in the process of designing a shared culture and rules, and designing the spaces to be as reshapable as possible, as it is virtually impossible to foresee the future needs of the spaces (e.g. Nenonen et al., 2015).

For instance, some studies indicate that in new kinds of offices with no designated desks, employees may be recurrently burdened by having to look for a suitable workspace for their task at hand (Bosch-Sijtsema, Ruohomäki, \& Vartiainen, 2010). This challenge indicates insufficient surveying of employee needs regarding spaces allocated for different kinds of tasks. The process of creating a shared culture around the use of spaces is equally crucial in reaping the benefit of their potential, and requires deliberate collaborative effort. For example, it is not uncommon for a group of employees to have very different ideas of what a quiet space means, and if there is no common agreement on how to use the spaces, their initial purpose becomes futile. Through shared practices, employees are not only engaging in self-regulation but also in co-regulation (Miller, Järvelä, 
\& Hadwin, 2017).

Although the effect of the physical environment on productivity and well-being may have been disregarded to a certain degree, the impact of digitalization on cognitive functioning has been of great interest to the academic community for many years. The current research literature on the impact of digital tools and applications on well-being and productivity is vast and partly conflicting. On one hand, along with the increasing number of digital devices and applications, the environment has become charged with more stimuli. This may lead to recurrent multitasking, interruptions and information overload, which results in impaired cognitive functioning in comparison to the capacity one would have without these challenges (Pashler, 1994; Salo, Salmela, Salmi, Numminen, \& Alho, 2017). Having constant access to work-related communication through different information channels via mobile devices and no fixed working hours may lead to insufficient boundaries for the working day or lack of rest and recovery after it (Vartiainen \& Hyrkkänen, 2010; Zijlstra \& Sonnentag, 2006). On the other hand, digitalization offers innumerable opportunities to significantly ease employees' mental burdens by enabling simpler tasks to be carried out automatically and reserving valuable human resources for complex tasks that require creative and collaborative problem-solving. It also offers many unforeseen possibilities for enriching one's skills and expertise regardless of one's geographical location or financial resources. In addition, various digital applications have been developed to reduce information overload: The tools have been harnessed to solve some of the challenges that they themselves generate.

Along with the massive shift towards knowledge intensive, digitally mediated work, new aspects of occupational health are becoming more focal. Cognitive ergonomics is one of these employers and employees need to pay attention to reducing unnecessary mental burden in order to facilitate productivity and well-being. Excessive mental "noise" can be seen as both external and internal: Abundant stimuli, interruptions and multitasking may originate in both one's surroundings and one's mind (e.g. Varao-Sousa, Smilek, \& Kingstone, 2018). Both can be regulated through proactive strategies: External stimuli by behavioral strategies, for example, deliberately arranging one's surroundings and tools to be supportive and uninterruptive of one's core tasks and turning off unnecessary notifications; and internal stimuli by learning and practicing different kinds of mental strategies such as awareness skills. The training program to be presented includes both of these approaches.

\section{Aims}

The general research question of the study was: How can individuals and communities use modern work environments and tools in ways that support productivity and well-being? The study aimed to respond this question by combining two emphases. First, it aimed to obtain more understanding of the physical, digital, social and psychological aspects of the knowledge intensive, multi-locational work environments and of their role in productivity and well-being (Study 1 and 
Study 2). Second, it aimed to develop the training program further on the basis of the results of the analysis (Study 2), and to utilize the knowledge gained in the development process to further understand the phenomena.

The specific research questions of the Study 1 and the Study 2 were as follows:

Study 1: What kind of support do organizations and individuals need to be able to use multi-locational spaces and digital tools in ways that support productivity and well-being? (RQ1).

Study 2: Can individuals and organizations benefit from training in how to use multi-locational spaces and digital tools in ways that support productivity and well-being; and if so, how? (RQ2).

The research questions were operationalized in the following way. The Study 1 examined the current situation and the special characteristics and needs of each organization regarding selected focal areas identified in the literary review, i.e. basic psychological needs as well as perceptions of the work environment. The Study 2 examined the trainee-reported changes and possible benefits resulting from training. In addition, it also aimed to further develop the training on the basis of the feedback, and to identify possible challenges or deficiencies in the training process.

Our study approach could thus be described as design research, the focus of which is both theoretical and pragmatic, and the research process of which advances in an iterative manner, designing, implementing and analyzing the training program and the related phenomena (Edelson, 2002). Although design-based research does not aim to develop universal theories or frameworks, it develops generalizable knowledge with an intermediate theoretical scope (Obrenovic, 2011).

\section{Method}

\subsection{Context of Study: Training Program}

The training program (Sjöblom, Lammassaari, Huovinen, \& Lonka, 2016; Sipila, Starck, \& Wegmuller, 2017; Starck, Sjöblom, Sipilä, Lammassaari, Aberg, \& Lehtinen-Toivola, 2017) aimed to promote well-being and productivity at work by developing the participants' awareness skills and behavioral strategies related to physical spaces, digital tools and more general aspects of knowledge work. The training aimed to work on both the individual and organizational level: The participants worked on the training topics both individually and collaboratively with fellow trainees from their organization and their managers and coworkers in order to determine how the training would best benefit their organization's prevailing development needs and what kinds of shared practices would be beneficial.

The partner organizations were deliberately chosen to represent diverse organizational structures to ensure genuine opportunities for the participants to share and learn best practices beyond organizational characteristics and boundaries. The training aimed to make use of not only the trainers' expertise, but also 
the diverse perspectives of the participants from different workplaces and organizational cultures.

The training was carried out twice in order to develop it further on the basis of observations and feedback acquired from the first round. The data and results reported in this article are based on the first round of the training (see the timeline of the training program and the study in Figure 1).

The training process lasted six months and consisted of three phases. In the first phase the starting point for the training topics was analyzed in each organization. We carried out a questionnaire study (Study 1) on work practices and well-being in each organization. The analyzed results were then elaborated on together with the trainees. In addition, to identify the focal needs in terms of physical spaces and tools, we also examined the physical work environment and its usability using walk-through usability mapping (for related methods to assess the usability of workplaces: see e.g. Rasila, Rothe, \& Nenonen, 2009). This mapping was carried out collaboratively by the trainers and trainees at each workplace.

The second phase of the training program was the active training process. This consisted of 12 workshops and the processing of topics between the workshops on a collaborative digital platform. Most of the workshops were carried out face to face, but some were digitally mediated. This way the topics of the digitally mediated work also became a part of the training itself. The participants were offered a practical opportunity to reflect on and experiment with useful practices for remote working, also with trainees from different organizations and different kinds of working cultures.

The training was led by a multidisciplinary team from the fields of behavioral sciences and business. The workshop topics covered the physical and digital work environment as part of human performance, behavioral strategies and knowledge practices as part of knowledge work, organizational culture, change management, motivation and engagement, stress and well-being and mindfulness. The guiding theoretical principles behind the training followed the current knowledge on the prerequisites for learning and motivation: The role of the participants was very active in the process and the trainers facilitated rather than instructed (Deci \& Ryan, 2000; Lonka, 2018). The participants themselves, together with their managers, determined which areas of the training were the most important to focus on from the perspective of their organization's prevailing situation. For some this was developing the physical environment to better meet the needs of their work, for others it was working with practices that support well-being at work and a sustainable working culture. In addition, throughout the training, the participants reflected on the training topics in their own learning diaries which also aimed to support the learning process and the participants' active role in directing it.

The third and final phase was the completion of the training. This included an analysis of the situation at the end of the training process from the participants' 
perspective (Study 2). The participants also made a development plan for their organization on the basis of the topics elaborated on and identified in the training process. The process of development and change was essentially seen as continuous and dynamically evolving, not separate or limitable to a specific period of time. It continued beyond the training as the participants still acted as transformation agents at their own workplaces, communicating with fellow employees and initiating purposeful practical experimentations together with their managers.

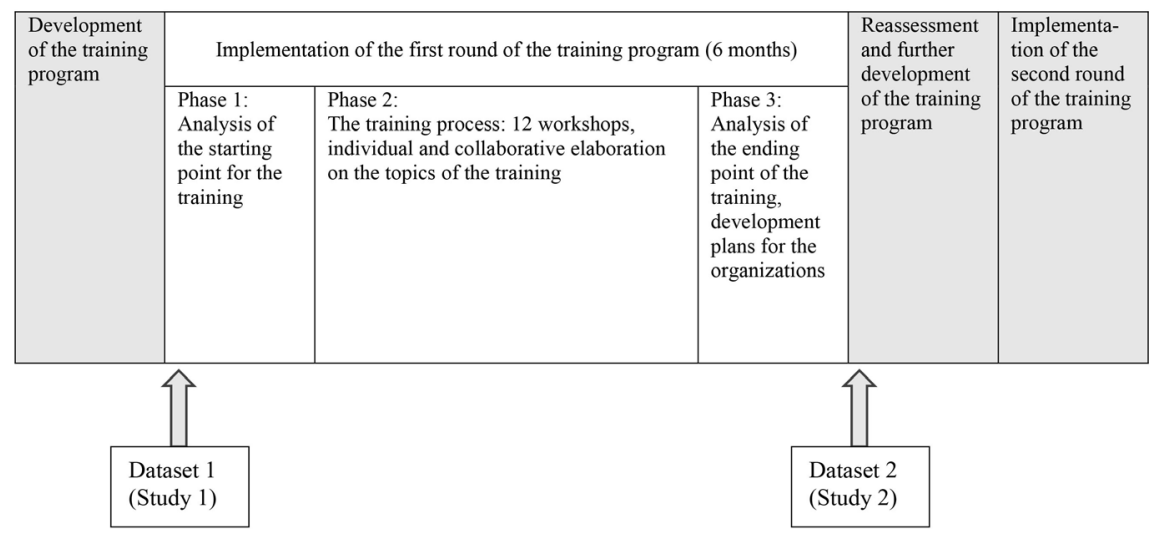

Figure 1. Timeline of the training program and the study.

\subsection{Study 1}

\subsubsection{Participants}

Before the training program, in order to examine the focal challenges in each organization, a larger sample of employees $(n=189)$ responded to a questionnaire on work practices and well-being at work. These participants were sampled from the participating organizations $(n=8,1$ municipal organization and 7 startup companies) and from organizations with no training attendees $(\mathrm{n}=2,1$ university of applied sciences and 1 university) in order to ensure more diversity in the comparisons of the issues of interest. For the purposes of comparisons between groups, the startup companies (7) were pooled into one group.

\subsubsection{Instruments}

Basic psychological needs at the workplace were assessed using the Basic Psychological Need Satisfaction at Work Scale (Deci, Ryan, Gagné, Leone, Usunov, \& Kornazheva, 2001; Kasser, Davey, \& Ryan, 1992). It included 21 items tapping into the three components of basic psychological needs; autonomy (e.g. "I feel like I can make a lot of inputs to deciding how my job gets done."), competence (e.g. "Most days I feel a sense of accomplishment from working.") and relatedness (e.g. "I really like the people I work with."). The scale was translated into Finnish by the 1 st author. The items were measured on a scale ranging from $1=$ not at all true to $7=$ very true. Composite scores of the three components were used in the analyses (see Table 1 for descriptive and internal consistency values). 
Perceptions of the work environment were assessed with a set of 12 items designed to cover different aspects of the participants' physical (e.g. "The physical spaces at my workplace support collaboration."), digital (e.g. "I find that the technology at my workplace helps me do my work.") and social (e.g. "Employees play an active role at the workplace.") work environment, ranging from possibilities to engage in quiet work to supportive social climate at work (the origin of the items: see references for Perceptions of the Work Environment). These items were measured on a scale ranging from $1=$ completely disagree to $5=$ completely agree or from $1=$ never to $7=$ daily (digital practices). Descriptive values are presented in Table 1.

Table 1. Descriptive values and internal consistencies of basic psychological needs satisfaction at work and perceptions of the work environment.

\begin{tabular}{|c|c|c|c|c|c|c|c|}
\hline Variable & $\mathrm{N}$ & Min & Max & Mean & S.E. & SD & $\alpha$ \\
\hline \multicolumn{8}{|l|}{ Basic psychological needs } \\
\hline Autonomy & 191 & 1.57 & 7.00 & 4.99 & 0.07 & 0.92 & 0.73 \\
\hline Competence & 191 & 3.00 & 7.00 & 5.67 & 0.06 & 0.83 & 0.66 \\
\hline Relatedness & 191 & 1.00 & 7.00 & 5.23 & 0.07 & 0.97 & 0.83 \\
\hline \multicolumn{8}{|l|}{ Physical } \\
\hline $\begin{array}{l}\text { 1) The physical spaces at my workplace support } \\
\text { collaboration. }\end{array}$ & 189 & 1.00 & 5.00 & 2.83 & 0.10 & 1.40 & - \\
\hline $\begin{array}{l}\text { 2) The physical spaces at my workplace help } \\
\text { employees concentrate. }\end{array}$ & 189 & 1.00 & 5.00 & 3.18 & 0.09 & 1.23 & - \\
\hline $\begin{array}{l}\text { 3) My workplace provides peaceful surroundings } \\
\text { for work. }\end{array}$ & 188 & 1.00 & 5.00 & 3.36 & 0.08 & 1.14 & - \\
\hline 4) The work environment is very significant to me. & 189 & 1.00 & 5.00 & 4.35 & 0.06 & 0.80 & - \\
\hline \multicolumn{8}{|l|}{ Digital } \\
\hline $\begin{array}{l}\text { 5) I find that the technology at my workplace } \\
\text { helps me do my work. }\end{array}$ & 188 & 1.00 & 5.00 & 3.48 & 0.08 & 1.15 & - \\
\hline $\begin{array}{l}\text { 6) I look online for ideas, instructions and materials } \\
\text { for my work. }\end{array}$ & 190 & 1.00 & 7.00 & 6.05 & 0.08 & 1.06 & - \\
\hline $\begin{array}{l}\text { 7) I ask my colleagues for help in work-related } \\
\text { matters online. }\end{array}$ & 189 & 1.00 & 7.00 & 4.64 & 0.14 & 1.90 & - \\
\hline $\begin{array}{l}\text { 8) The employees of my workplace work in an } \\
\text { online community (e.g. Facebook group, Google } \\
\text { group). }\end{array}$ & 187 & 1.00 & 7.00 & 4.04 & 0.17 & 2.33 & - \\
\hline \multicolumn{8}{|l|}{ Social } \\
\hline 9) Employees play an active role at the workplace. & 188 & 1.00 & 5.00 & 3.56 & 0.08 & 1.14 & - \\
\hline $\begin{array}{l}\text { 10) My superior encourages employees to express } \\
\text { their opinions at the workplace. }\end{array}$ & 189 & 1.00 & 5.00 & 3.55 & 0.09 & 1.17 & - \\
\hline $\begin{array}{l}\text { 11) My superior is interested in how the } \\
\text { employees are. }\end{array}$ & 188 & 1.00 & 5.00 & 3.49 & 0.09 & 1.26 & - \\
\hline 12) I feel happy at my workplace. & 189 & 1.00 & 5.00 & 3.57 & 0.08 & 1.08 & - \\
\hline
\end{tabular}




\subsubsection{Procedures}

To answer the research aims of Study 1 we conducted a set of univariate analyses of variance to compare the selected organizations with regard to the basic psychological needs satisfaction at workplace as well as perceptions of the physical, digital and social work environments. All analyses were conducted using IBM Statistical Package for Social Sciences 25.

\subsection{Study 2}

\subsubsection{Participants}

At the end of the training program, the trainees $(n=15)$ responded to a questionnaire on possible changes resulting from training. The trainees were employees of a large public organization and several startup companies in the Finnish metropolitan area. Altogether eight organizations participated and one to four participants from each organization attended the training program.

\subsubsection{Instruments}

The questionnaire included sixteen questions on possible changes to work practices, the use of digital devices and applications, the use of physical spaces, productivity, well-being, motivation, social aspects of work, experiences of change, experiences of the most focal benefits of the training, and suggestions for further improvement of the training. The questions included both multiple choice and open-ended questions. Because of the nature of the research question and the limited sample size, this analysis focused on the open-ended questions. The questions were designed by the authors (Appendix).

\subsubsection{Procedures}

The content analysis of the qualitative reports on the possible changes resulting from training was phenomenon-driven. It refrained from making strong presumptions or specific hypotheses that would have limited it. Rather, as the framework of the training program was relatively new, it seemed best to leave room for the perceptions of the participants themselves. The analysis was thus data driven, aiming at a more general conceptual understanding through inductive reasoning.

\section{Results}

\subsection{Study 1}

As indicated in Figure 2 and Table 2, the participants from the startup companies had significantly higher autonomy satisfaction at work than the participants from the municipal organization and the university of applied sciences. Furthermore, the participants from the university had significantly higher autonomy satisfaction at the workplace than the participants from the municipal organization. The participants' competence satisfaction at the workplace was relatively high in all four organizations, and we found no statistically significant differences between them. Regarding relatedness satisfaction at the workplace, the 


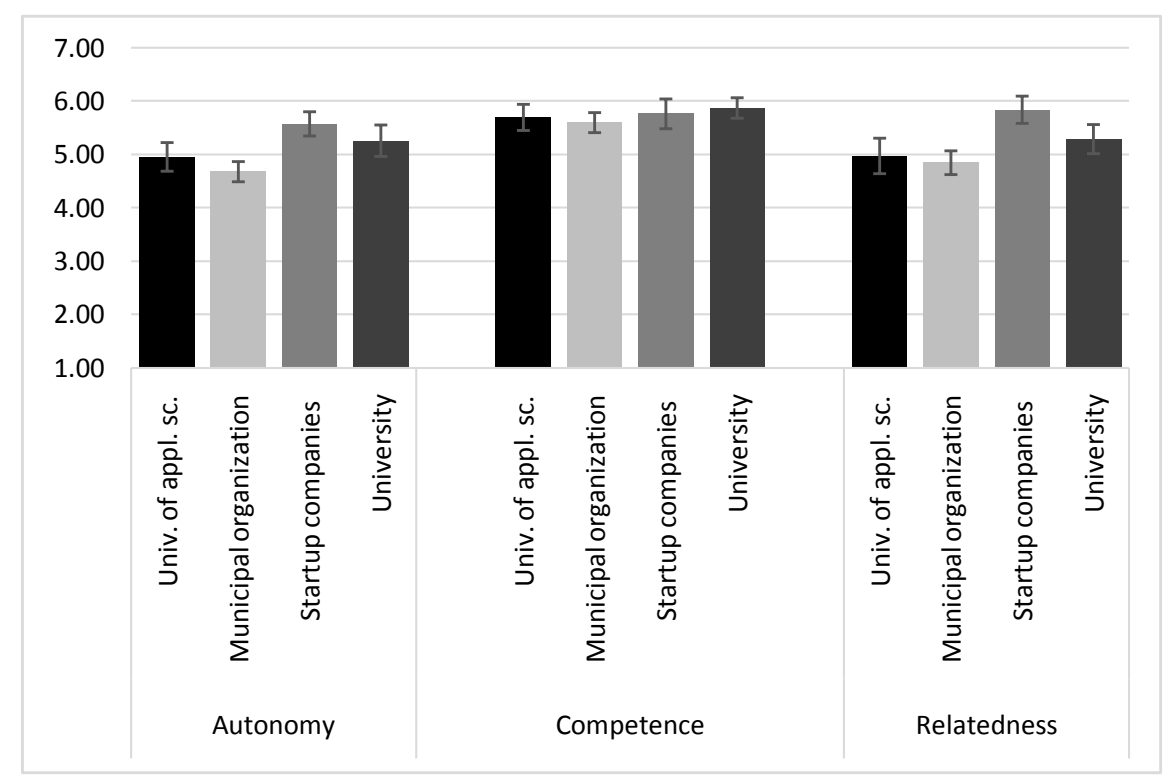

Figure 2. Differences between organizations in basic psychological needs satisfaction at the workplace.

Table 2. Differences between organizations in basic psychological needs satisfaction at the workplace.

\begin{tabular}{cccccccccccc}
\hline \multicolumn{1}{c}{ Group } \\
& $\begin{array}{c}\text { University of } \\
\text { applied sciences } \\
\mathrm{N}=36\end{array}$ & $\begin{array}{c}\text { Municipal } \\
\text { organization } \\
\mathrm{N}=85\end{array}$ & $\begin{array}{c}\text { Startup } \\
\text { companies } \\
\mathrm{N}=34\end{array}$ & $\begin{array}{c}\text { University } \\
\mathrm{n}=34\end{array}$ & & \\
\hline Variable & $\mathrm{M}$ & $\mathrm{SD}$ & $\mathrm{M}$ & $\mathrm{SD}$ & $\mathrm{M}$ & $\mathrm{SD}$ & $\mathrm{M}$ & $\mathrm{SD}$ & $\mathrm{F}(3,186)$ & $p$ \\
\hline Autonomy & $4.96_{\mathrm{ab}}$ & 0.80 & $4.68_{\mathrm{b}}$ & 0.89 & $5.58_{\mathrm{c}}$ & 0.68 & $5.26_{\mathrm{ac}}$ & 0.88 & 10.61 & $<0.001$ \\
Competence & 5.70 & 0.73 & 5.60 & 0.88 & 5.77 & 0.83 & 5.88 & 0.57 & 1.05 & 0.37 \\
Relatedness & $4.98_{\mathrm{a}}$ & 0.99 & $4.85_{\mathrm{a}}$ & 1.05 & $5.84_{\mathrm{b}}$ & 0.76 & $5.29_{\mathrm{ab}}$ & 0.81 & 9.44 & $<0.001$ \\
\hline
\end{tabular}

Note: Groups sharing the same subscript did not differ statistically significantly at $\mathrm{p}<0.05$ with Bonferroni correction.

participants from the startup companies scored significantly higher than those from the municipal organization and the university of applied sciences.

The participants' perceptions of the physical, digital and social work environment (see Table 3) differed between organizations. The perceptions of how well the physical environment accommodated for the work appeared polarized: The environment appropriately accommodated for either collaborative tasks or tasks that require focused attention, peace and quiet; but rarely both. What also seemed to bear importance was that the mean of perceiving the work environment as significant was high across all the organizations; the importance of the work environment was clearly acknowledged by employees.

We also found differences between the perceptions of the digital environment and the related work practices. Despite minor differences it was common for participants in all organizations to utilize the internet for searching for informa- 
tion and material relevant to their work and field. We detected more diversity in the work tasks over the internet: Asking for help and working on tasks and deliverables on online platforms. Overall, the startup companies had more varied ways of utilizing digital technology in their work.

Finally, the participants' perceptions of the social work environment, in terms of, for example, employee agency, differed across the organizations. The work environment in startup companies was perceived as being the most encouraging of employees playing active roles at the workplace. The employees of the startup companies also perceived their work environment as supporting their opinions and initiatives. Even though their own role was rather autonomous, they felt that their superior was interested in how they were doing. They felt happy at their workplace.

Table 3. Differences between organizations in perceptions of the work environment.

\begin{tabular}{|c|c|c|c|c|c|c|c|c|c|c|c|}
\hline \multirow[b]{3}{*}{ Item } & \multicolumn{8}{|c|}{ Group } & \multirow[b]{3}{*}{$\mathrm{F}$} & \multirow[b]{3}{*}{$\mathrm{df}$} & \multirow[b]{3}{*}{$p$} \\
\hline & \multicolumn{2}{|c|}{$\begin{array}{l}\text { University of } \\
\text { applied sciences } \\
\mathrm{n}=36\end{array}$} & \multicolumn{2}{|c|}{$\begin{array}{l}\text { Municipal organi- } \\
\text { zation } \\
\mathrm{n}=85\end{array}$} & \multicolumn{2}{|c|}{$\begin{array}{c}\text { Startup } \\
\text { companies } \\
\mathrm{n}=34\end{array}$} & \multicolumn{2}{|c|}{$\begin{array}{l}\text { University } \\
\qquad \mathrm{n}=34\end{array}$} & & & \\
\hline & $\mathrm{M}$ & $\mathrm{SD}$ & $\mathrm{M}$ & $\mathrm{SD}$ & $\mathrm{M}$ & $\mathrm{SD}$ & M & $\mathrm{SD}$ & & & \\
\hline \multicolumn{12}{|l|}{ Physical } \\
\hline $\begin{array}{l}\text { 1) The physical spaces at my workplace } \\
\text { support collaboration. }\end{array}$ & 3.40 & 1.17 & $2.20_{\mathrm{a}}$ & 1.14 & 4.61 & 0.56 & $2.18_{\mathrm{a}}$ & 1.00 & 50.69 & 3,184 & 0.000 \\
\hline $\begin{array}{l}\text { 2) The physical spaces at my workplace } \\
\text { help employees concentrate. }\end{array}$ & $2.74 \mathrm{a}$ & 1.07 & $3.58_{\mathrm{b}}$ & 1.14 & $2.82_{\mathrm{a}}$ & 1.21 & $3.03_{\mathrm{ab}}$ & 1.34 & 6.15 & 3,184 & 0.001 \\
\hline $\begin{array}{l}\text { 3). My workplace provides peaceful } \\
\text { surroundings for work. }\end{array}$ & $3.26_{\mathrm{ab}}$ & 1.20 & $3.59_{\mathrm{a}}$ & 1.07 & $2.94_{b}$ & 1.22 & $3.33_{\mathrm{ab}}$ & 1.05 & 2.90 & 3,183 & 0.036 \\
\hline $\begin{array}{l}\text { 4) The work environment is very } \\
\text { significant to me. }\end{array}$ & $4.42_{\mathrm{a}}$ & 0.65 & $4.34_{\mathrm{a}}$ & 0.75 & $4.52_{\mathrm{a}}$ & 0.67 & $4.12_{\mathrm{a}}$ & 1.14 & 1.46 & 3,184 & 0.228 \\
\hline \multicolumn{12}{|l|}{ Digital } \\
\hline $\begin{array}{l}\text { 5) I find that the technology at my } \\
\text { workplace helps me do my work. }\end{array}$ & $3.91_{\mathrm{a}}$ & 0.98 & $3.14_{b}$ & 1.21 & $4.06_{a}$ & 1.01 & $3.44_{\mathrm{ab}}$ & 0.89 & 7.77 & 3,183 & 0.000 \\
\hline $\begin{array}{l}\text { 6) I look online for ideas, instructions and } \\
\text { materials for my work. }\end{array}$ & $6.11_{\mathrm{ab}}$ & 1.17 & $5.81_{\mathrm{a}}$ & 1.11 & $6.58_{\mathrm{b}}$ & 0.94 & $6.09_{\mathrm{ab}}$ & 0.75 & 4.36 & 3,185 & 0.005 \\
\hline $\begin{array}{l}\text { 7) I ask my colleagues for help in } \\
\text { work-related matters online. }\end{array}$ & $4.26_{\mathrm{a}}$ & 1.96 & $4.28_{\mathrm{a}}$ & 1.98 & 6.06 & 0.97 & $4.65_{\mathrm{a}}$ & 1.70 & 8.62 & 3,184 & 0.000 \\
\hline $\begin{array}{l}\text { 8) The employees of my workplace work in } \\
\text { an online community (e.g. Facebook group, } \\
\text { Google group). }\end{array}$ & $4.59 \mathrm{a}$ & 1.99 & $2.97_{b}$ & 2.03 & 6.53 & 1.37 & $3.82_{\mathrm{ab}}$ & 2.17 & 27.08 & 3,182 & 0.000 \\
\hline \multicolumn{12}{|l|}{ Social } \\
\hline $\begin{array}{l}\text { 10) My superior encourages employees to } \\
\text { express their opinions at the workplace. }\end{array}$ & $3.77_{\mathrm{a}}$ & 1.14 & $3.13_{\mathrm{b}}$ & 1.08 & 4.52 & 0.67 & $3.53_{\mathrm{ab}}$ & 1.16 & 14.47 & 3,184 & 0.000 \\
\hline $\begin{array}{l}\text { 11) My superior is interested in how the } \\
\text { employees are. }\end{array}$ & $3.69_{a}$ & 1.17 & $3.04_{\mathrm{b}}$ & 1.25 & 4.50 & 0.76 & $3.53_{\mathrm{ab}}$ & 1.16 & 13.10 & 3,183 & 0.000 \\
\hline 12) I feel happy at my workplace. & $3.60_{\mathrm{a}}$ & 0.98 & $3.27 \mathrm{a}$ & 1.12 & 4.39 & 0.75 & $3.56_{\mathrm{a}}$ & 0.86 & 10.24 & 3,184 & 0.000 \\
\hline
\end{tabular}

Note: Groups sharing the same subscript did not differ statistically significantly at $p<0.05$ with Bonferroni correction. 


\subsection{Study 2}

In the qualitative reports on possible changes resulting from training, the participants $(\mathrm{n}=15)$ reported changes on both the individual and organizational level (Table 4).

Table 4. Trainee-reported changes resulting from training program.

\begin{tabular}{|c|c|c|}
\hline & Enhanced awareness & Development of new practices \\
\hline Individual level & 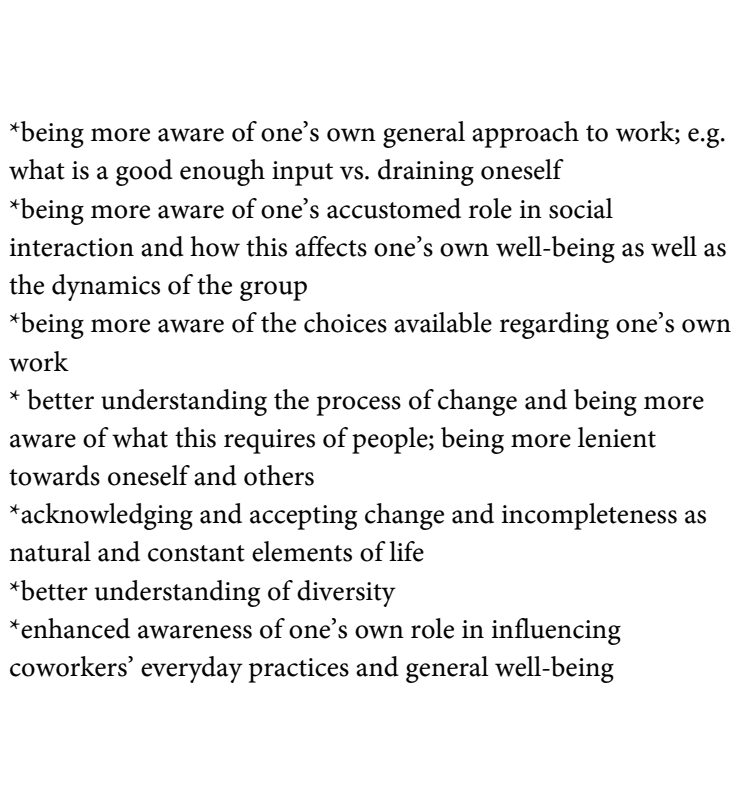 & $\begin{array}{l}\text { *starting to plan and manage one's own work more } \\
\text { systematically and proactively } \\
\text { * prioritizing work tasks } \\
\text { *starting to actively and deliberately reflect on work } \\
\text { practices as part of everyday work routine } \\
\text { *clarifying and setting boundaries for work, both during } \\
\text { the workday and at the interfaces between work and } \\
\text { leisure time } \\
\text { *starting to take breaks during the workday or generally } \\
\text { slowing down a little } \\
\text { *utilizing new practices in order to work more efficiently } \\
\text { and lightly, such as reducing multitasking related to } \\
\text { general work practices or using digital devices } \\
\text { *deliberately choosing purposeful modes of } \\
\text { communication, e.g. reducing unnecessary use of email } \\
\text { *actively seeking digital applications that facilitate work } \\
\text { and trying them out } \\
\text { *supporting and coaching others in their working methods } \\
\text { towards ease and efficiency } \\
\text { *practicing new leadership skills, in particular in leading } \\
\text { change }\end{array}$ \\
\hline
\end{tabular}

*setting up new meeting routines in the work community to actively and collaboratively discuss focal topics that emerged in the training

*communicating more explicitly, openly and actively, also inviting questioning of accustomed habits at the workplace *exploring new ways of working and trying them out in practice

${ }^{*}$ introducing useful new digital platforms and deliberately and critically reflecting on the function of each of them as well as those already in use

${ }^{*}$ co-designing and agreeing on shared digital strategies and knowledge practices, e.g. the intended purposes and kind of communication of each application * modifying the physical space to better meet work requirements, e.g. increasing the space reserved for quiet work or for taking breaks

First, many pointed out that through the training process they had become more aware of their personal ways of working as well as the implicit practices of the organization. They also described insights and changes in their work-related attitudes and thought processes. Second, they reported taking various practical steps towards developing more purposeful work practices, on both a personal and organizational level. Examples of these on the individual level were starting to plan and manage their work more systematically, including clarifying the 
boundaries of work both during the workday and at the interfaces between work and leisure time. On the organizational level, they reported communicating more explicitly and openly and questioning the accustomed ways of working, as well as making required changes to shared practices.

Table 4 describes the reported practical development procedures and changes in awareness in more detail, on both the individual and organizational level.

\section{Discussion}

This study focused on the main research question of how individuals and communities can use modern work environments and tools in ways that support productivity and well-being. The aim of the study was two-fold. First, it aimed to obtain more understanding of the physical, digital, social and psychological aspects of the knowledge intensive, multi-locational work environments and of their role in productivity and well-being. Second, it aimed to develop the training program further on the basis of the results of the analysis, and to utilize the knowledge gained in the development process to further understand the phenomena.

\subsection{Conclusions}

In response to the specific research questions, the results of this study indicate that the organizations differed in terms of their employees' basic psychological needs satisfaction as well as perceptions of their work environment. Accordingly, the organizations also had different needs regarding using multi-locational spaces and digital tools in ways that would support productivity and well-being (RQ1). During the training process the participants elaborated on these needs further. For some organizations, the need to develop physical spaces to better meet work requirements was focal, such as proper spaces for quiet work and breaks, whereas for others, preparing for a major work environment change in the organization was the key aspect. For some, the main developmental need was support of employee autonomy and relatedness, or the development of more purposeful usage of digital tools, either in terms of brushing up required competences, finding better suited digital applications, or agreeing on more deliberate and though-out shared practices related to these. All of these needs clearly contributed to both the productivity and well-being of the employees.

As regards the results regarding physical spaces and digital tools, the organizational culture of each organization was manifested in the way the physical spaces were designed and used. The organizations that had a strong collaboration culture and strong employee experience of relatedness tended to have work environments that were perceived as supportive of collaborative work but not necessarily of quiet, focused individual work. The reverse was true of the organizations that represented a more traditional approach to knowledge intensive expert work. Similarly, the organizations that were perceived as particularly supportive of employees' autonomy, namely the startup companies, were trying out new things and seemed to be ahead of the others with regard to their digital tool practices. Based on the participants' elaborations on the topics during the 
training process, it also appeared that a large part of the work and collaboration in startup companies took place in digital environments, and this was likely to affect the variety of ways in which the digital tools were used-they needed to complement face-to-face interaction in more diverse ways. In addition, the Study 1 showed that the startup companies seemed to have the most supportive social work environment in terms of both supporting employee autonomy and offering the employees the support that they needed. As explained in the theoretical background, this is crucial in modern knowledge work and its importance for both productivity and well-being should not be underestimated.

In the Study 2 (RQ2), the support offered by the training program was operationalized as supporting the analysis of the current situation and the setting of goals, offering information and tools for beneficial practices, supporting the development of the participants' awareness skills and diverse behavioral strategies related to physical spaces, digital tools and more general aspects of knowledge work, and facilitating the development process as it occurred in each of the participating organizations. The training operated on both the individual and organizational level, and it strongly emphasized the participants' active role, which was essential due to the diversity of the central developmental needs.

Both individuals and organizations were able to benefit from training in the use of multi-locational spaces and digital tools in ways that support productivity and well-being, which is presented in more detail in the results section (RQ2). According to the participants' reports, the training program succeeded in supporting the development of awareness skills, offering the participants new information, tools and insights into well-being and productivity at work, and helping the participants identify essential individual and organizational development needs and to proactively start working on these (RQ2). Measuring knowledge worker productivity has been found to be challenging (Ramírez \& Nembhard, 2004), and changes in productivity were not measured in this study. However, the changes in work practices that the participants described were such that are known to directly affect both productivity and well-being; for example, taking sufficient breaks. To conclude, this study shows it is fruitful to offer individuals and organizations support in the form of training programs to help them find proactive ways to manage multi-locational, digitally-mediated knowledge work and the psychological resources available for it.

\subsection{Practical Implications}

In addition to studying the results of the training, the Study 2 also aimed to further develop the training and to identify possible challenges or deficiencies in the training process. Based on the observations, results and feedback from the first round of the training described in this article, a few structural aspects of the training were developed further. In the second round of the training, in order to better support the developmental work of the trainees in their organizations, the management was more closely involved in the process, and at least two partici- 
pants from each organization were included in the program. In order to utilize the information gained in the questionnaire study and the usability mapping more extensively and to include a more active role of the management, a new phase was added between the analysis of the starting point (Phase 1) and the active training process (Phase 2). On the basis of the information acquired in the Phase 1, the new Phase 2 included recognizing the most essential needs for change in the organization and setting meaningful and realistic goals for the training. This was carried out in each organization collaboratively among the trainees, the management and the trainers of the training program.

As noted in the conclusions of Study 1, often physical spaces indeed demonstrate the culture of the community using them, in how the spaces are designed but also in under what kinds of explicit or implicit agreements they are used (e.g. Mälkki, Sjöblom, \& Lonka, 2014). However, regardless of organizational culture, all knowledge work typically involves both collaborative and quiet, independent work (Vartiainen et al., 2007). From the employee well-being and productivity perspective, it would be highly beneficial if work environments were less polarized and more diverse in terms of the facilities that they provide and the activities that they support, so that they could offer their employees sufficient spaces for the different kinds of work tasks that they must do as part of their work. One option for this is a multi-space office; however, again the space itself does not resolve all challenges-emphasis and elaboration on developing a meaningful shared working culture are crucial (Hakkarainen, 2009).

This study highlights the need for $21^{\text {st }}$ century skills in working life. Examples of these skills include self-regulation, cognitive load management, the ability to collaborate in networked systems and to use digital tools. More attention needs to be paid to actively developing the needed competencies and practices related to modern environments and tools, on both the individual and organizational level. This needs to be done not only at schools but also in the working life. The results of this study show that training programs can successfully support the development of the needed competencies.

It is important to further develop materials and evidence-based trainings in order to offer the needed support. Developing meaningful new practices and deliberately choosing to maintain ones that work well, first requires awareness of the current situation in identifying focal needs, second, learning about beneficial practices and practical tools, and third, often also support in the development process. In the middle of the daily hassle and the abundance of tasks and stimuli it is often challenging to gain clarity on what is essential, what needs to change and what does not, and how to make the needed changes.

Finally, the importance of small everyday actions and practices related to well-being and productivity in knowledge work should not be underestimated. The potential risks of modern environments and tools are not minor issues; they affect health and productivity worldwide on a daily basis (Sparks, Faragher, \& Cooper, 2001; Helliwell, Layard, \& Sachs, 2019; WHO, 2013). Thus, developing 
seemingly small practices of everyday well-being and productivity can actually be seen as a form of preventative work on mental health as well as a considerable factor affecting GDP.

\subsection{Limitations and Future Directions}

As regards work culture, in the future it would be useful to differentiate between the cultures of the individual, team and organization. Social interaction, knowledge sharing, and collective problem solving is relational in nature and varies depending on individuals, communities and larger networks (Hakkarainen, Palonen, Paavola, \& Lehtinen, 2004). Personal, social and institutional knowledge practices may thus all represent different work cultures. However, this study was limited by the structure of the training and the focus of the funding organization, which was to develop organizations by working with the individuals representing them. Thus, it was beyond the scope of this project to look at the team level more closely. In addition, as the organizations represented very different kinds of structures, the division between organizational and team level would have been slightly artificial for some of them-in the startup companies formed by a very small group of employees, organizational level was often the same as team level, whereas the large organizations had more distinct team and organizational levels.

This study utilized mixed methodology in order to gain an understanding of a relatively new topic. It demonstrated the need for scientifically established scales to assess physical spaces, digital tools and related work practices as well as more general strategies and self-regulation regarding knowledge work. For these reasons, this study was restricted to approaching the research questions with a rather simple comparative methodology. However, following this study and in order to serve these needs in the future, a new scale measuring broad self-regulatory skills in multi-locational knowledge work has been developed and piloted (Sjöblom, Hietajärvi, \& Salmela-Aro, accepted for publication). As further regards the limitations of this study, the sample size in the qualitative analysis was modest due to practical limitations such as the number of participants that could be included in the training program. Future research calls for more rigorous research designs with more representative samples as well as the development of quantitative scales to study the topic and expand on the results of this study.

Furthermore, it would also be important to assess the long-term effects of the training on well-being and productivity. As the training process entailed active processing of the topics until the end, the developmental steps were also likely to happen after the training. Unfortunately, in this case, the funding and the timeline of the project did not allow for this. Similarly, the changes should also be measured on the organizational level-in this case the assessment of effects was limited to being based on the trainees' perspectives of changes on both the individual and organizational level. In addition, as the training program consisted of a few core elements, it would be beneficial to study whether these are equally 
important with regard to the benefits of the training.

\subsection{Contribution}

Although modern knowledge intensive, multi-locational, digitally mediated work comes with its specific challenges and the knowledge on the various helpful and challenging aspects of it is extensive, interventions and training programs addressing these issues have been sparse. This study brought together the research traditions of work and organizational psychology, educational psychology, motivational psychology and occupational health research in order to utilize the existing multidisciplinary knowledge as a comprehensive basis for the study and the training program. The training program developed in this study responded to the aforementioned challenges of modern work and opened new ground for further elaboration and developmental work on the topic.

From the theoretical and practical perspective, this study contributes to the current understanding of how to utilize multi-locational spaces and digital tools in ways that support the productivity and well-being of employees. Human potential is the most valuable resource not only in knowledge intensive organizations but also in modern societies. A fluent everyday work routine, as well as any significant creative input or innovation, entails fostering employees' psychological resources. Proactive strategies for doing this can be purposefully developed on both the individual and organizational level, and this supports not only productivity but also the general well-being of employees.

\section{Acknowledgements}

This study was funded by the European Social Fund project 3 spaces-Towards Inspiring Workplaces (first and second authors; project number 6303956), the Academy of Finland project Bridging the Gaps (third author; project number 308352) and the Finnish Ministry of Education and Culture project Phenomenal Teacher Education-Blended Learning Environments (third author; project number 6605844) as well as by personal grants from the Finnish Cultural Foundation, the University of Helsinki and the Finnish Work Environment Fund (first author) and a publishing grant from the Faculty of Educational Sciences, University of Helsinki.

The initial idea for the training program was designed by Professor Kirsti Lonka; Head of RDI, Kitte Marttinen; Doctoral Researcher, Kirsi Sjöblom; and Project Manager, Suvi Starck. The training program was developed by a project group consisting of Doctoral Researcher, Heidi Lammassaari; Senior Lecturer, Anita Lehtinen-Toivola; Project Specialist, Anu Sipilä; Project Manager, Suvi Starck; Doctoral Researcher, Kirsi Sjöblom; and Senior Lecturer, Monica Åberg (AL-T, KM, AS, SS and MÅ/Haaga-Helia University of Applied Sciences Ltd.; $\mathrm{HL}, \mathrm{KL}$ and KS/University of Helsinki).

Authors' contributions: KS had the leading role in planning the study and writing the article. KS and HL had the main responsibility for planning the data 
collection and carrying it out. KS, HL and KL designed the questionnaire used in Study 2. KS and LH conducted the analyses and collaborated in the presentation of the results of Study 1 as well as the methodological part in general. KS and HL conducted the analyses and collaborated in the presentation of the results of Study 2. KM supervised the work on the manuscript and collaborated especially in the focus, structure and theoretical substance of the study. KL supervised and collaborated in both the training program and the research and publication of the results. She was also the Principal Investigator of the project. All authors contributed to the substance of the article.

We warmly thank the participants of the training program for their contribution to the research and Project Manager Suvi Starck for her help in collecting the data for the study.

\section{Conflicts of Interest}

The authors declare no conflicts of interest regarding the publication of this paper.

\section{References}

Ananiadou, K., \& Claro, M. (2009). 21st Century Skills and Competences for New Millennium Learners in OECD Countries. OECD Education Working Papers, No. 41, Paris: OECD Publishing. https://doi.org/10.1787/218525261154

Bakker, A. B., \& Demerouti, E. (2007). The Job Demands-Resources Model: State of the Art. Journal of Managerial Psychology, 22, 309-328.

https://doi.org/10.1108/02683940710733115

https://www.isonderhouden.nl/doc/pdf/arnoldbakker/articles/articles_arnold_bakker_ 159.pdf

Bishop, S. R., Lau, M., Shapiro, S., Carlson, L., Anderson, N. D., Carmody, J., Devins, G. et al. (2004). Mindfulness: A Proposed Operational Definition. Clinical Psychology: Science and Practice, 11, 230-241. https://doi.org/10.1093/clipsy.bph077

Boekaerts, M., Zeidner, M., \& Pintrich, P. R. (2000). Handbook of Self-Regulation. Amsterdam: Elsevier. https://doi.org/10.1016/B978-012109890-2/50030-5

Bosch-Sijtsema, P. M., Ruohomäki, V., \& Vartiainen, M. (2010). Multi-Locational Knowledge Workers in the Office: Navigation, Disturbances and Effectiveness. New Technology, Work and Employment, 25, 183-195.

https://doi.org/10.1111/j.1468-005X.2010.00247.x

Brinkley, I. (2006). Defining the Knowledge Economy. London: The Work Foundation.

Deci, E., \& Ryan, R. (2014). The Importance of Universal Psychological Needs for Understanding Motivation in the Workplace. In M. Gagné (Ed.), The Oxford Handbook of Work Engagement, Motivation, and Self-Determination Theory (pp. 13-32). Oxford: Oxford Library of Psychology.

Deci, E. L., \& Ryan, R. M. (2000). The "What" and "Why" of Goal Pursuits: Human Needs and the Self-Determination of Behavior. Psychological Inquiry, 11, 227-268.

https://doi.org/10.1207/S15327965PLI1104_01 https://users.ugent.be/ wbeyers/scripties2011/artikels/Deci\&Ryan_2000.pdf

Deci, E. L., Ryan, R. M., Gagne, M., Leone, D. R., Usunov, J., \& Kornazheva, B. P. (2001). Need Satisfaction, Motivation, and Well-Being in the Work Organizations of a Former 
Eastern Bloc Country: A Cross-Cultural Study of Self-Determination. Personality and Social Psychology Bulletin, 27, 930-942. https://doi.org/10.1177/0146167201278002 https://selfdeterminationtheory.org/SDT/documents/2001_DeciRyanGagneLeoneEtal.pdf

De Paoli, D. (2015). Virtual Organizations: A Call for New Leadership. In A. Ropo, P. Salovaara, E. Sauer, \& D. De Paoli (Eds.), Leadership in Spaces and Places (pp. 109-127). Cheltenham: Edward Elgar Publishing. https://doi.org/10.4337/9781783477920.00014

Edelson, D. C. (2002). Design Research: What We Learn When We Engage in Design. The Journal of the Learning Sciences, 11, 105-121. https://doi.org/10.1207/S15327809JLS1101_4

El-Farr, H. K. (2009). Knowledge Work and Workers: A Critical Literature Review (Vol. 1, No. 1, pp. 1-15). Leed: Leed University Business School, Working Paper Series.

Gareis, K. (2003). Home-Based vs. Mobile Telework: The Interrelationship between Different Types of Telework. In B. Rapp, \& P. Jackson (Eds.), Organization and Work beyond 2000 (pp. 171-185). Berlin: Springer Science and Business Media. https://doi.org/10.1007/978-3-642-57346-0_14

Gelles, D. (2015). Mindful Work: How Meditation Is Changing Business from the Inside Out. Boston, MA: Houghton Mifflin Harcourt.

Hakkarainen, K. (2009). A Knowledge-Practice Perspective on Technology-Mediated Learning. Computer-Supported Collaborative Learning, 4, 213-231. https://doi.org/10.1007/s11412-009-9064-x

Hakkarainen, K., Palonen, T., Paavola, S, \& Lehtinen, E. (2004). Communities of Networked Expertise: Professional and Educational Perspectives. Bingley: Emerald Group Publishing Limited.

Harrison, A., Wheeler, P., \& Whitehead, C. (2004). The Distributed Workplace: Sustainable Work Environments. London: Routledge. https://doi.org/10.4324/9780203616574

Helliwell, J., Layard, R., \& Sachs, J. (2019). World Happiness Report 2019. New York: Sustainable Development Solutions Network.

Hislop, D., \& Axtell, C. (2009). To Infinity and Beyond? Workspace and the Multi-Location Worker. New Technology, Work and Employment, 24, 60-75. https://doi.org/10.1111/j.1468-005X.2008.00218.x

Huber, S. (2015). Novel Work-How Do Large-Scale Companies Respond to the Pressure Created by the Evolving Work? Conference Presentation, REWORK'15-Future Work and Environment, Helsinki, Finland.

Hutchins, E. (2000). Distributed Cognition. In International Encyclopedia of the Social and Behavioral Sciences (pp. 2068-2072). Amsterdam: Elsevier.

https://doi.org/10.1016/B0-08-043076-7/01636-3

https://arl.human.cornell.edu/linked\%20docs/Hutchins_Distributed_Cognition.pdf

Ipe, M. (2003). Knowledge Sharing in Organizations: A Conceptual Framework. Human Resource Development Review, 2, 337-359. https://doi.org/10.1177/1534484303257985

Janssen, M., Heerkens, Y., Kuijer, W., Van Der Heijden, B., \& Engels, J. (2018). Effects of Mindfulness-Based Stress Reduction on Employees' Mental Health: A Systematic Review. PLoS ONE, 13, e0191332. https://doi.org/10.1371/journal.pone.0191332

Kanfer, R., \& Kanfer, F. H. (1991). Goals and Self-Regulation: Applications of Theory to Work Settings. In M. L. Maehr, \& P. R. Pintrich (Eds.), Advances in Motivation and Achievement (pp. 287-326). Greenwich: JAI Press.

Karasek, R. A., \& Theorell, T. (1990). Healthy Work: Stress, Productivity and the Reconstruction of Working Life. New York: Basic Books.

Kasser, T., Davey, J., \& Ryan, R. M. (1992). Motivation, Dependability, and Em- 
ployee-Supervisor Discrepancies in Psychiatric Vocational Rehabilitation Settings. Rehabilitation Psychology, 37, 175-187. https://doi.org/10.1037/0090-5550.37.3.175

Lonka, K. (2018). Phenomenal Learning from Finland. Helsinki: Edita Publishing.

Lonka, K., \& Mind the Gap Research Group (2015). Working Document I. In European Parliament (Ed.), Innovative Schools: Teaching and Learning in the Digital Era: Workshop Documentation (pp. 5-46). Brussels: European Parliament.

Miller, M., Järvelä, S., \& Hadwin, A. (2017). Self-Regulation, Co-Regulation, and Shared Regulation in Collaborative Learning Environments. In Handbook of Self-Regulation of Learning and Performance (pp. 99-122). Abingdon-on-Thames: Routledge.

Mälkki, K., Sjöblom, K., \& Lonka, K. (2014). Transformation of the Physical Space and Transformation of the Subject. In A. Nicolaides, \& D. Holt (Eds.), Spaces of Transformation and Transformation of Space: Proceedings of the XI International Transformative Learning Conference (pp. 550-556). New York: Teachers College, Columbia University.

Nenonen, S., Airo, K., Bosch, P., Fruchter, R., Koivisto, S., Gersberg, N., Rothe, P., Ruohomäki, V., \& Vartiainen, M. (2009). Managing Workplace Resources for Knowledge Work. ProWork Project Report.

Nenonen, S., Kärnä, S., Junnonen, J. M., Tähtinen, S., Sandström, N., Airo, K., \& Niemi, O. (2015). How to Co-Create Campus? Tampere: Juvenes Print.

Norman, D. A. (1993). Things That Make Us Smart: Defending Human Attributes in the Age of the Machine. Cambridge, MA: Perseus Books.

Obrenovic, Ž. (2011). Design-Based Research: What We Learn When We Engage in Design of Interactive Systems. Interactions, 18, 56-59. https://obren.nl/papers/dbr.pdf https://doi.org/10.1145/2008176.2008189

Ojala, S., \& Pyöriä, P. (2018). Mobile Knowledge Workers and Traditional Mobile Workers: Assessing the Prevalence of Multi-Locational Work in Europe. Acta Sociologica, 61, 402-418. https://doi.org/10.1177/0001699317722593

Parsons, R., \& Hartig, T. (2000). Environmental Psychophysiology. In J. T. Cacioppo, L. G. Tassinary, \& G. Berntson (Eds.), Handbook of Psychophysiology (pp. 815-846). New York: Cambridge University Press.

Pashler, H. (1994). Dual-Task Interference in Simple Tasks: Data and Theory. Psychological Bulletin, 116, 220. http://laplab.ucsd.edu/articles/Pashler_PB1994.pdf https://doi.org/10.1037/0033-2909.116.2.220

Powell, A., Piccoli, G., \& Ives, B. (2004). Virtual Teams: A Review of Current Literature and Directions for Future Research. The Database for Advances in Information Systems, 35, 6-36. https://www.researchgate.net/publication/220627357 https://doi.org/10.1145/968464.968467

Ramírez, Y. W., \& Nembhard, D. A. (2004). Measuring Knowledge Worker Productivity: A Taxonomy. Journal of Intellectual Capital, 5, 602-628. https://doi.org/10.1108/14691930410567040 https://www.researchgate.net/profile/David_Nembhard/publication/235268678_Measu ring_Knowledge_Worker_Productivity_A_Taxonomy/links/0c96053ac2d9aed2920000 00.pdf

Rasila, M. H., Rothe, P., \& Nenonen, S. (2009). Workplace Experience: A Journey through a Business Park. Facilities, 27, 486-496. https://doi.org/10.1108/02632770910996333

Rüdiger, K., \& McVerry, A. (2007). Exploiting Europe's Knowledge Potential: “Good Work" or "Could Do Better". Knowledge Work and Knowledge Workers in Europe. A Report Prepared for the Knowledge Economy Programme. London: The Work Foundation. 
Ryan, R. M., \& Deci, E. L. (2000). Self-Determination Theory and the Facilitation of Intrinsic Motivation, Social Development, and Well-Being. American Psychologist, 55, 68-78. https://doi.org/10.1037/0003-066X.55.1.68

Ryan, R. M., \& Deci, E. L. (2017). Self-Determination Theory: Basic Psychological Needs in Motivation, Development, and Wellness. New York: Guilford Press.

Salo, E., Salmela, V., Salmi, J., Numminen, J., \& Alho, K. (2017). Brain Activity Associated with Selective Attention, Divided Attention and Distraction. Brain Research, 1664, 25-36. https://doi.org/10.1016/j.brainres.2017.03.021

Sipila, A., Starck, S., \& Wegmuller, M. (2017). 3TILAA Muutosagentti Valmennus Kohti innostavaa tyopaikkaa. Helsinki: Haaga-Helia University of Applied Sciences Ltd. https://www.theseus.fi/handle/10024/144273

Sjöblom, K., Lammassaari, H., Huovinen, S., \& Lonka, K. (2016). 3SPACES-Towards Inspiring Workplaces. Enhancing Well-Being and Co-Creating Purposeful Work Practices through Mental, Physical and Virtual Modalities. Conference Presentation, Nordic Working Life Conference 2016, Tampere, Finland.

Sjöblom, K., Mälkki, K., Sandström, N., \& Lonka, K. (2016). Does Physical Environment Contribute to Psychological Needs? A Self-Determination Theory Perspective on Learning in the Chemistry Laboratory. Frontline Learning Research, 4, 17-39. https://doi.org/10.14786/flr.v4i1.217

Sjöblom, K., Hietajärvi, L., \& Salmela-Aro, K. (Accepted for Publication). The Importance of Broad Self-Regulatory Skills in Multi-Locational Knowledge Work-Introducing a New Questionnaire Instrument.

Sparks, K., Faragher, B., \& Cooper, C. L. (2001). Well-Being and Occupational Health in the 21st Century Workplace. Journal of Occupational and Organizational Psychology, 74, 489-509. https://doi.org/10.1348/096317901167497 https://pdfs.semanticscholar.org/4c36/160d588084ff2240cef7a0639d890b42a171.pdf

Starck, S., Sjoblom, K., Sipila, A., Lammassaari, H., Aberg, M., \& Lehtinen-Toivola, A. (2017). 3TILAA-Muutosagentti Valmennus. 3SPACES-Transformation Agent Training Program. Audiovisual Material: Video Training Program. Helsinki: Haaga-Helia Yritysyhteistyo.

https://www.youtube.com/watch?v=TXrkClXkwGk\&list=PLYjNcJ1jQZybv7_-TPK02C a-WSGDgHL2L

Varao-Sousa, T. L., Smilek, D., \& Kingstone, A. (2018). In the Lab and in the Wild: How Distraction and Mind Wandering Affect Attention and Memory. Cognitive Research: Principles and Implications, 3, 42. https://doi.org/10.1186/s41235-018-0137-0

Vartiainen, M., \& Hyrkkänen, U. (2010). Changing Requirements and Mental Workload Factors in Mobile Multi-Locational Work. New Technology, Work and Employment, 25, 117-135. https://doi.org/10.1111/j.1468-005X.2010.00243.x

Vartiainen, M., Hakonen, M., Koivisto, S., Mannonen, P., Nieminen, M. P., Ruohomaki, V., \& Vartola, A. (2007). Distributed and Mobile Work: Places, People and Technology. Helsinki: Otatieto.

Vermunt, J. D., \& Verloop, N. (1999). Congruence and Friction between Learning and Teaching. Learning and Instruction, 9, 257-280. https://doi.org/10.1016/S0959-4752(98)00028-0

World Health Organization WHO (2013). Mental Health Action Plan 2013-2020. http://www.who.int/mental_health/publications/action_plan/en

Zijlstra, F. R., \& Sonnentag, S. (2006). After Work Is Done: Psychological Perspectives on Recovery from Work. European Journal of Work and Organizational Psychology, 15, 129-138. https://doi.org/10.1080/13594320500513855 
Perceptions of the Work Environment: The Questions on the Physical and Social Environment Were Developed as a Part of the RYM Indoor Environment Project 2012-2014, Finnish Funding Agency for Technology and Innovation, Project Number 462054; and the Flexible Places for Learning Spaces Project 2014-2016, City of Espoo, Aalto University, University of Helsinki and Finnish National Agency for Education; the Questions on the Digital Environment Were Developed as Part of the Mind the Gap Research Project 2013-2016, Academy of Finland, Project Number 1265528; All the Projects Were Led on Behalf of the University of Helsinki by Professor Kirsti Lonka. 


\section{Appendix}

\section{Study 2: Questions on possible changes resulting from training}

Note: Scale for multiple choice questions 1 - 14: 1 not at all true - 5 completely true; each question followed up by an open-ended question.

\section{TRAINING PROCESS}

Please assess your experiences of the training process. Please also consider small-scale everyday practices and possible changes to them.

Through this training

1) My way of working has changed.

If so, how?

2) My attitude towards work has changed.

If so, how?

3) My way of using workspaces has changed.

If so, how?

4) My way of utilizing digital tools or applications has changed.

If so, how?

5) My way of planning and scheduling my own work has changed.

If so, how?

6) My way of acting as a member of the work community has changed.

If so, how?

7) My way of viewing change has changed.

If so, how?

8) My way of viewing incompleteness has changed.

If so, how?

9) My well-being at work has changed.

If so, how?

10) My work motivation has changed.

If so, how?

11) My work performance has changed.

If so, how?

12) My work community's work practices have changed.

If so, how?

13) The atmosphere in my work community has changed.

If so, how?

14) I plan to implement what I have learned during the training process at my 
workplace.

If so, what?

15) What for you was the main benefit of the training process?

16) How would you further develop the training process? 